\title{
Reverse phase chromatographic behaviour of major components in Capsicum Annuum extract
}

\author{
Monica Butnariu ${ }^{1 *}$, Angela Caunii ${ }^{2}$ and Salomeia Putnoky ${ }^{3}$
}

\begin{abstract}
Background: The purpose of the study is to develop a suitable analytical method in order to establish appropriate conditions for isolation and assay of the dominant compounds in extracts of Capsicum annuum.

Results: The studies are performed with standard substances to establish the HPLC conditions for complete separation of capsaicin and dihydrocapsaicin, the two major components of interest. Because of their prevalent apolar features, reverse phase chromatographic version was approached. Systematic studies on different eluents revealed the $65 \%$ methanol-35\% water mixture as a proper mobile phase providing a complete separation of the components according to analytical claims.

Conclusions: The results may be of interest to develop a specific analytical procedure with advanced specificity for quantitative assay of capsaicin and dihydrocapsaicin in pharmaceutical products and in foods.
\end{abstract}

\section{Background}

The two major components in C. annum are capsaicin (C) and dihydrocapsaicin (DHC). The only difference between them is the presence of a carbon-carbon double bond [1].

Capsaicin (8-methyl- $N$-vanillyl-6-nonenamide) has CAS No.: 404-86-4; molecular formula: $\mathrm{C}_{18} \mathrm{H}_{27} \mathrm{NO}_{3}$ and molecular weight: 305.42. Dihydrocapsaicin (8-Methyl$\mathrm{N}$-vanillylnonenamide/N-(4-Hydroxy-3-methoxybenzyl) -8-methylnonanamide) has CAS No.: 19408-84-5, molecular formula: $\mathrm{C}_{18} \mathrm{H}_{29} \mathrm{NO}_{3}$ and molecular weight: 307.43 . Capsaicin subject hydrogenation turns dihidrocapsaicin [2]. Capsaicin is a capsaicinoid alkaloid with notable thermal stability retaining its activity even boiling [3]. It is only slightly soluble in water [4], but very soluble in ethanol and vegetable oils [5]. Other capsaicinoids are dihydrocapsaicin, nordihydrocapsaicin, homocapsaicin and homodihydrocapsaicin [6]. These are present in certain pharmaceutical products [7] or in foods [8]. From the multiple possibilities, the chromatographic technique with liquid mobile phase [9] performed at high pressure (HPLC) offers several advantages such as:

\footnotetext{
* Correspondence: monicabutnariu@yahoo.com

'Chemistry and Vegetal Biochemistry, Banat's University of Agricultural Sciences and Veterinary Medicine from Timisoara, Calea Aradului no. 119, 300645 Timisoara, Romania

Full list of author information is available at the end of the article
}

the possibility of automating and computer processing the method [10]; advanced reproducibility, both in identifying the isolated compounds [11], and in the quantitative determinations [12]; the possibility of performing the analyses in a relatively short period of time [13]; and the non-destructive aspect of the analysis, the isolated components being subject to further studies [14]. Suitable methods of isolation and analysis should be useful for assessing the distribution of capsaicinoids in foods and in clarifying the roles of these biologically active substances in plant, diet, and medicine.

\section{Results}

The standard solutions used in the series of experiments with variable eluent composition, contained $0.24 \mathrm{mg} / \mathrm{mL}$ and $0.15 \mathrm{mg} / \mathrm{mL}$ capsaicine and dihydrocapsaicine respectively. The mentioned components in the following concentrations: capsaicin and dihydrocapsaicin. The chromatograms of a standard solution containing both capsaicin and dihydrocapsaicin are presented in Figures 1, 2, 3, $4,5,6,7$ and 8 with indication of the mobile phase composition as well. It is found that the eluent mixture of $65 \%$ methanol and 35\% water is convenient for the isolation of these components, even in complex samples. This eluent is able to completely separate the two components ("up to the base line") without extended peak broadening. An exaggerated broadening of the peaks of interest may result
(C) Chemistry Central

(c) 2012 Butnariu et al.; licensee Chemistry Central Ltd. This is an Open Access article distributed under the terms of the Creative Commons Attribution License (http://creativecommons.org/licenses/by/2.0), which permits unrestricted use, distribution, and reproduction in any medium, provided the original work is properly cited. 


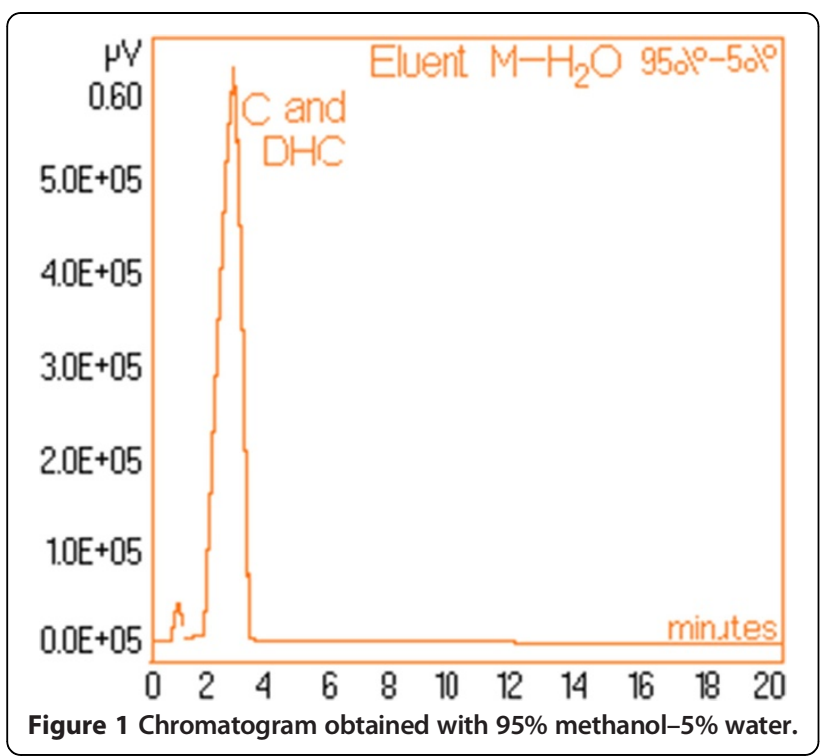

in accidental overlap with foreign peaks of "ballast" components possibly present in real samples [15].

For quantitative determinations, calibration of the chromatographic signals (the area under the peaks) is required separately for capsaicin and dihydrocapsaicin. The details concerning the preparation of standard solutions and the associate areas of peaks are shown in Table 1. For each standard solution a volume of $20 \mu \mathrm{L}$ was injected into the column. The calibration plot for capsaicine and dihydrocapsaicine are presented in Figures 9 and 10. The calibration plot covers the concentration interval of $0.192-1.554 \mathrm{mg} / \mathrm{mL}$ for capsaicin, with a correlation coefficient higher than 0.994 , and the concentration interval of $0.055-0.444 \mathrm{mg} / \mathrm{mL}$ for dihydrocapsaicin, with a

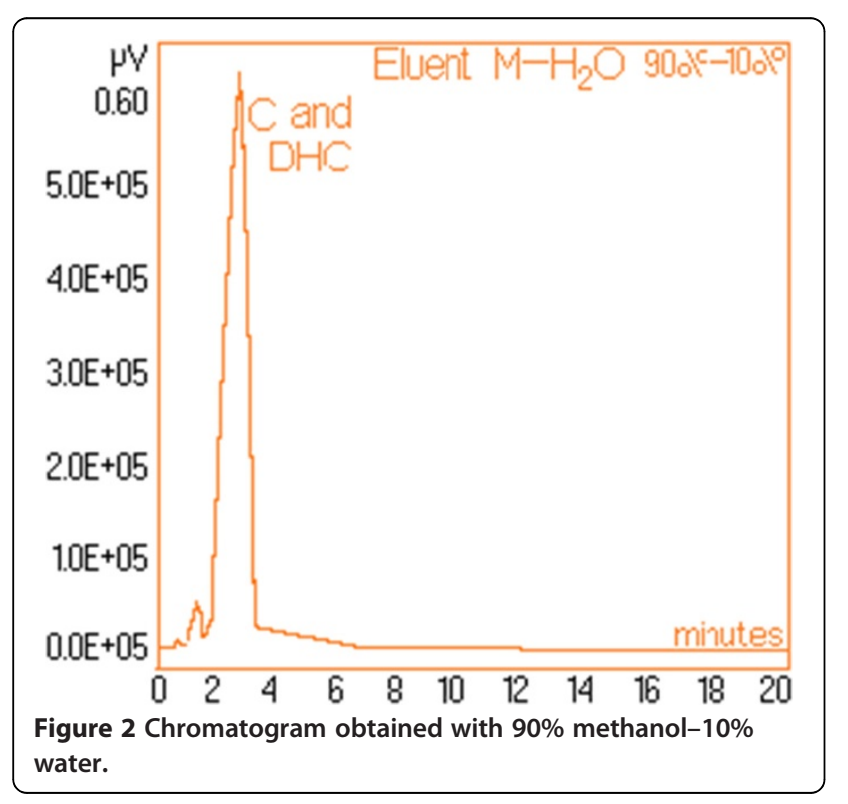

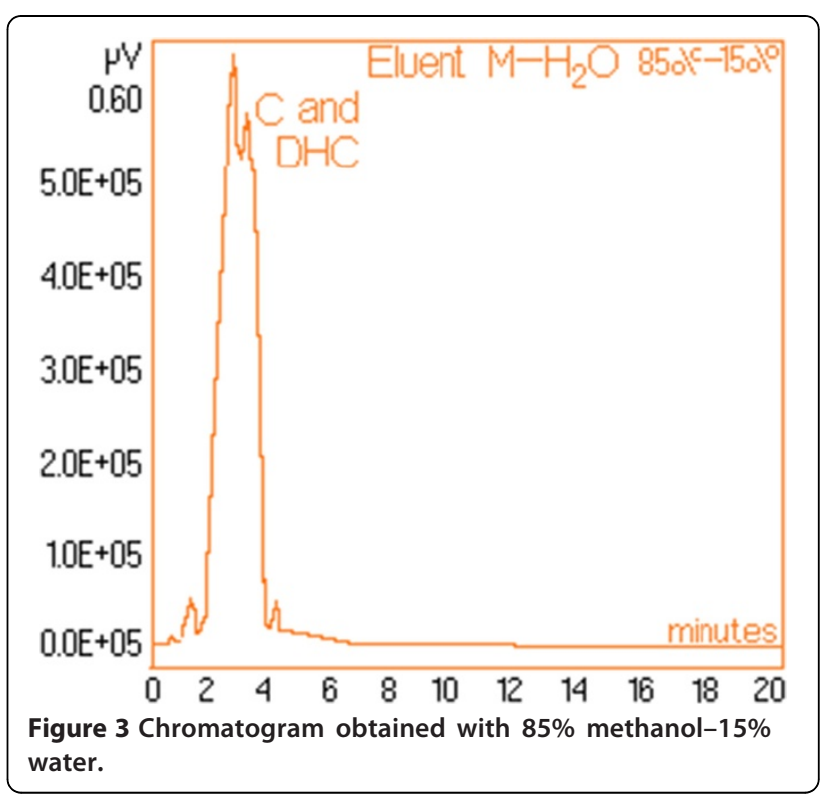

correlation coefficient higher than 0.981 . The real samples (C. annuиm) were previously diluted with anhydrous methanol in volumetric ratio of $1: 10$, and then injected a volume of $20 \mathrm{~mL}$ into the chromatographic column. Figure 11 presents the relevant portion of the chromatogram obtained. Figure 12 shows dependence of the retention time's difference for the two components, to the volumetric percentage of water in eluent. The points align on a curve having a relatively simple form and monotone variation. Figure 13 shows the linearized version of the aforementioned dependence.

\section{Discussion}

The chromatograms of Figures 1, 2, 3, 4, 5, 6, 7 and 8 shows a monotone increase of retention times both for capsaicin and dihydrocapsaicin with the volumetric

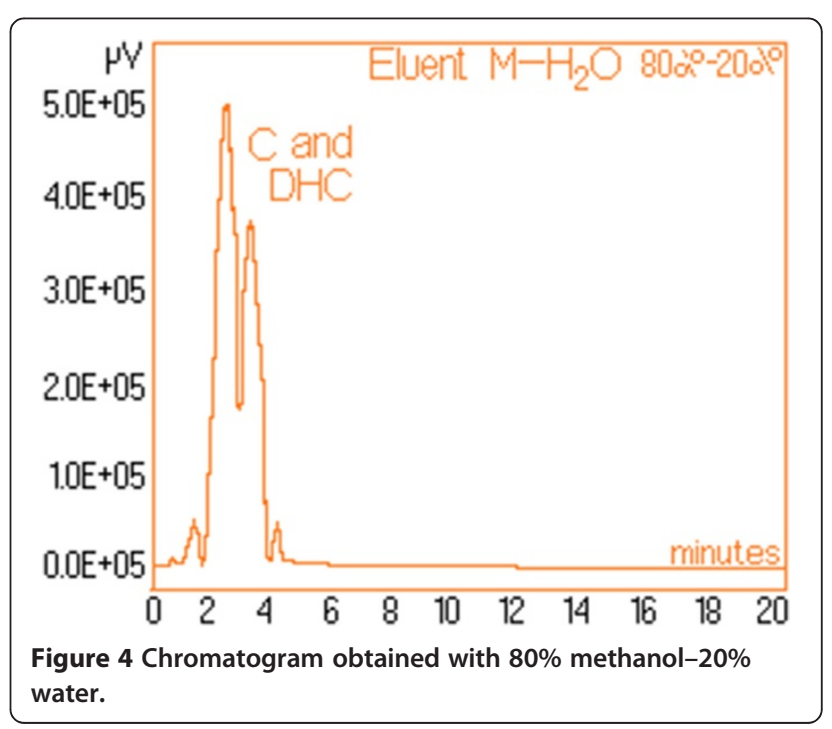




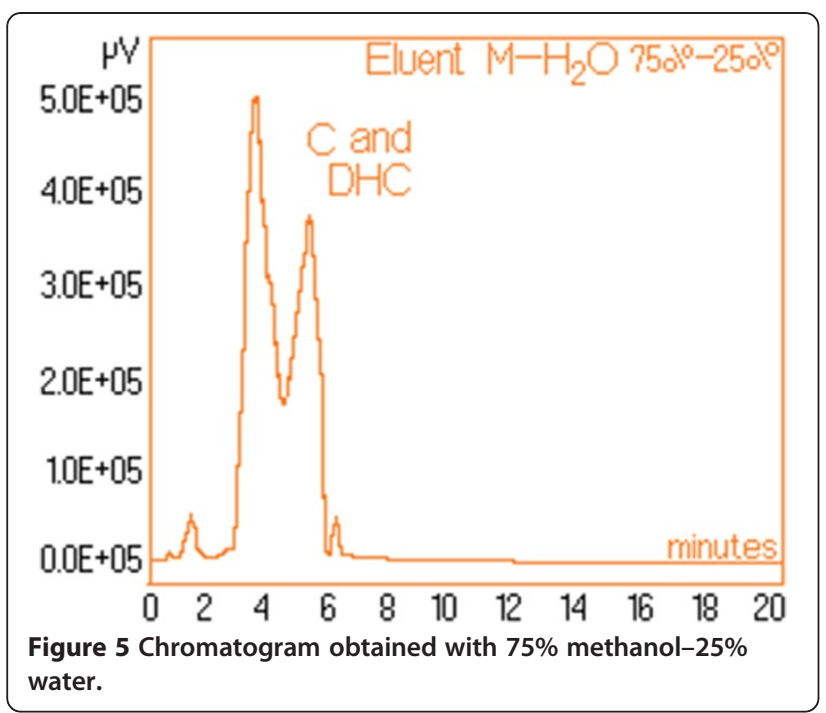

percentage of water in the eluent mixture. The correlation of these variables is illustrated in Figure 12.

According to known studies and theories concerning the chromatographic migration in reverse phase chromatographic systems [16], the logarithm of retention times are in linear relationship with the polarity of the mobile phase (Figure 13). The found linear relationship demonstrates that in the retention mechanism of capsaicin and dihydrocapsaicin, prevails the same type of interaction (the hydrophobic interaction).

Taking into account the practical aspects [17] for relevant analyses, there were selected the conditions in which the chromatograms from Figures 1, 2, 3, 4, 5, 6, 7 and 8 were obtained.

In Figure 11 it is observed that in the chromatogram of real samples (C. annuum), besides the chromatographic signals of interested components, there appear, with impressive intensities, other peaks belonging to "ballast"

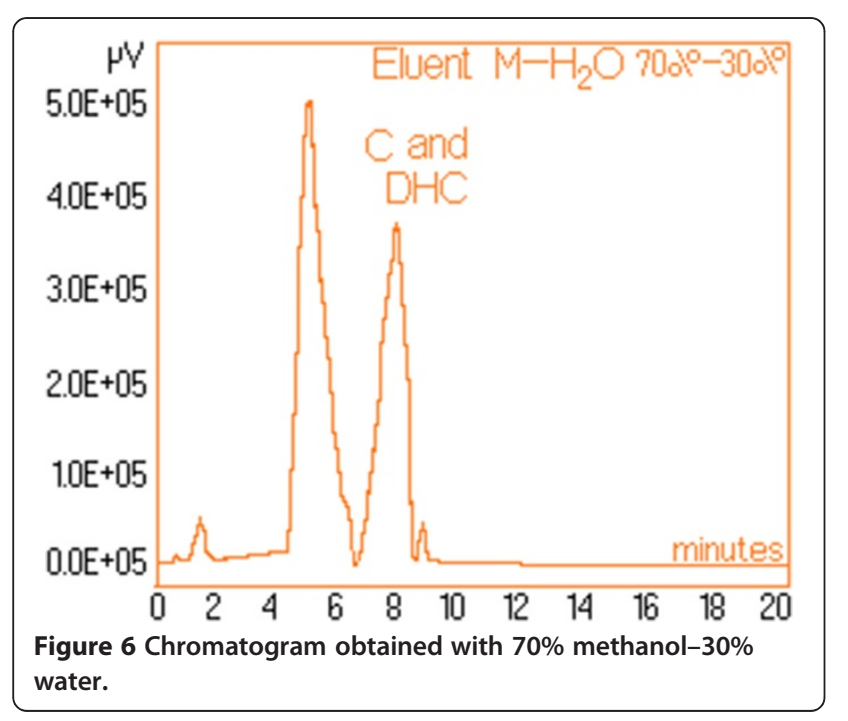

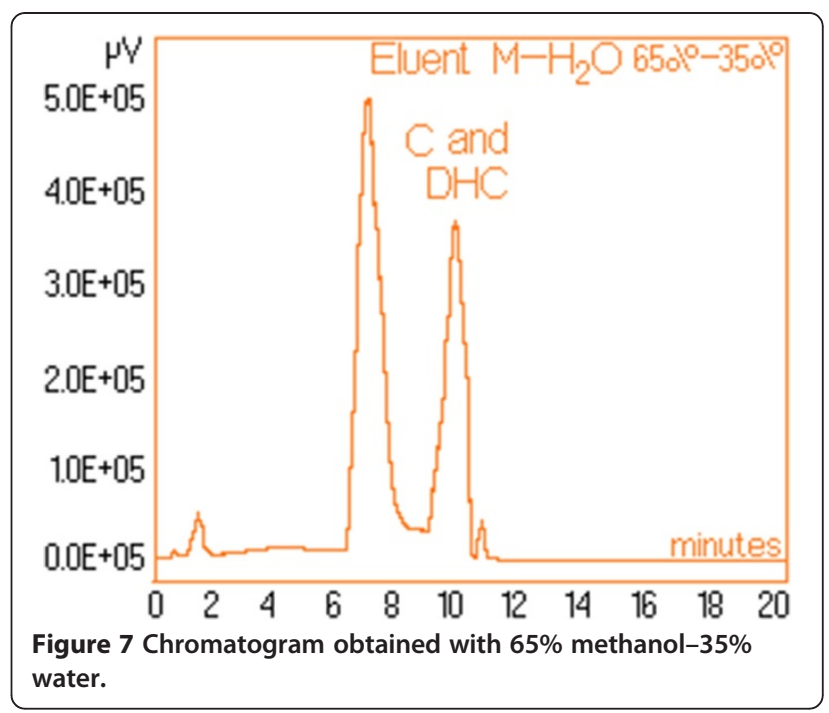

components. However, the interested signals are visible and can be integrated without difficulties [18]. Table 2 contains the results of analyses performed on a series of 16 C. annuum extracts, randomly chosen from different batches but from the same producer.

It is noticed that the individual values of concentrations, for both components, oscillate within relatively close limits, proving that the 16 extracts from different samples of $C$. annuum, although coming from different batches, had resembling compositions. In this situation, by adequately modifying the eluent composition [19], we can reach a similar situation to that presented in Figure 12, situation in which the signals of the two components can be evaluated conveniently.

\section{Conclusions}

This assay represents a method for the isolation and the quantitative analysis of secondary capsaicinoid metabolites

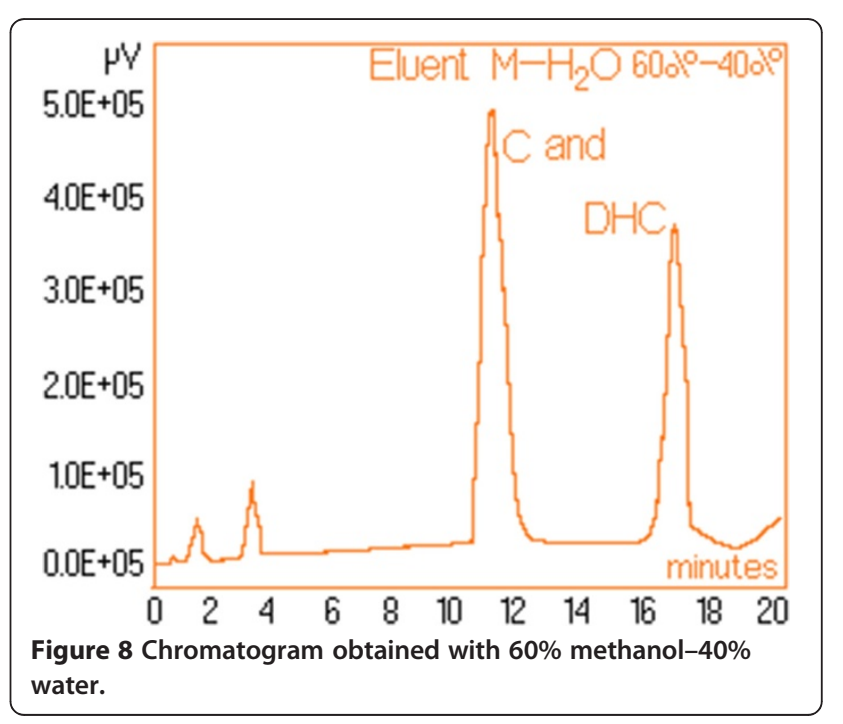


Table 1 Capsaicin and Dihydrocapsaicin standard solutions data

\begin{tabular}{lllll}
\hline No. & $\begin{array}{l}\text { Conc. } \mathbf{C} \\
(\mathbf{m g} / \mathbf{m L})\end{array}$ & $\begin{array}{l}\text { Conc. DHC } \\
(\mathbf{m g} / \mathbf{m L})\end{array}$ & $\begin{array}{l}\text { Aria C } \\
(\boldsymbol{\mu} \mathbf{V} \cdot \mathbf{m i n})\end{array}$ & $\begin{array}{l}\text { Aria DHC } \\
(\boldsymbol{\mu} \mathbf{V} \cdot \mathbf{m i n})\end{array}$ \\
\hline 1 & 0.192 & 0.055 & 713888.5 & 456893.8 \\
\hline 2 & 0.388 & 0.111 & 1442649.6 & 923306.2 \\
\hline 3 & 0.777 & 0.222 & 2889017.4 & 1848992.1 \\
\hline 4 & 1.165 & 0.333 & 4331667.0 & 2772298.3 \\
\hline 5 & 1.554 & 0.444 & 5778034.8 & 3697984.2 \\
\hline
\end{tabular}

(capsaicin and dihydrocapsaicin), in 16 fruit samples of the Capsicum (Solanaceae) plant was investigated. The HPLC method was optimized by highlighting the effects on retention times of the composition of the mobile phase (methanol and water mixture). Based on the area defined by the signals of components (shown in columns 2 and 4 , in Table 2) and with the calibration lines build with known standard solutions (Figures 9 and 10), there were determined the concentrations of the components in the solutions of real samples. Obviously, the concentrations in the original samples were 10 times higher (because of the dilution), than the ones read directly from Figures 9 and 10. The concentrations of capsaicin and dihydrocapsaicin, expressed in $\mathrm{mg} / \mathrm{mL}$, in extracts from C. annuum, are presented in the columns 3 and 5 , in Table 2 . The described and successfully tested analytical method, in the case of C. annuиm allows, with little modifications if needed, the isolation and assay of the two components even in presence of a large quantity of "ballast" components.

In conclusion, it been shown that the nonpolar stationary phase and a mobile phase composed of $65 \%$ methanol and $35 \%$ water is suitable for a good chromatographic separation and a convenient assay of capsaicinoids (capsaicin and dihydrocapsaicin).

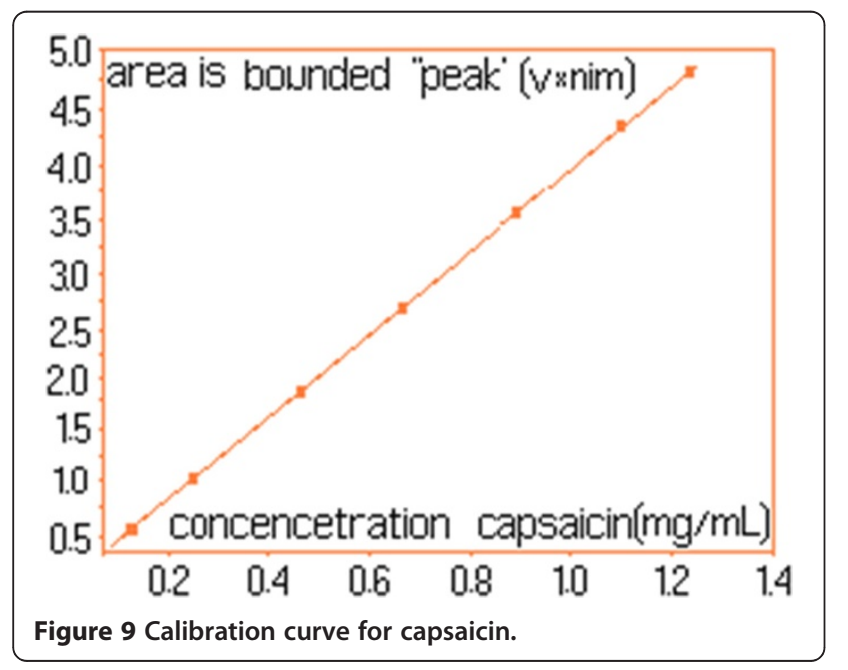

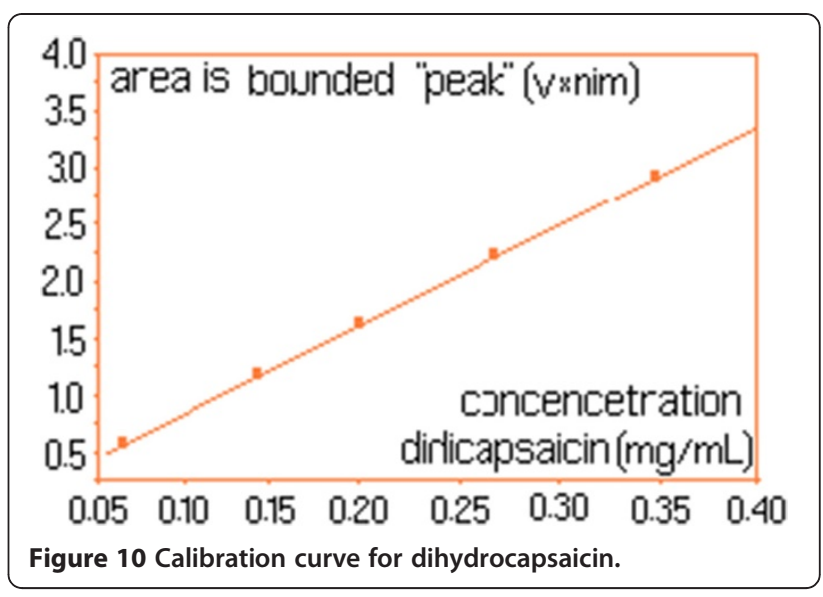

\section{Methods}

Plant material

The fruits of C. annuum were collected from the local laboratory cultures in western Romania. The samples used for assays were retained, numbered and stored in the Biochemistry plant refrigerator. For the preparation of the eluent mixture, anhydrous methanol (Merck, spectroscopic purity "Uvasol") and standard solutions of capsaicin and dihydrocapsaicin of the same brand were used.

\section{Capsaicinoid isolation}

Prior to grinding, bags containing pod samples from each of the 16 samples were taken out of the freezer and allowed to reach room temperature prior to opening, in order to prevent moisture condensation onto the pod surface. Representative fruits were ground with a GM 200 (Grindomix) mill to pass a 20 screen mesh, not more than a week prior to capsaicinoid isolation. The powder $(0.200 \mathrm{~g})$ was accurately weighed into 2 vials, $2 \mathrm{~mL}$ of $\mathrm{N}$, $\mathrm{N}$-dimethylformamide (DMF) was added and the vial was sealed with Teflon-lined screw caps. Extraction was carried out at $80^{\circ} \mathrm{C}$ in a dry block heater for $1 \mathrm{~h}$. Samples were swirled every $15 \mathrm{~min}$ during the $1 \mathrm{~h}$ period to assure

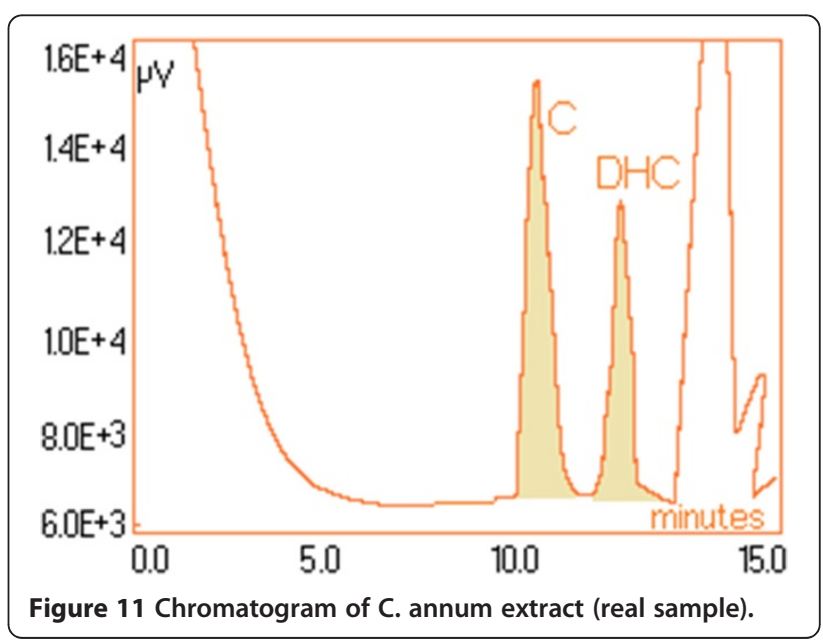




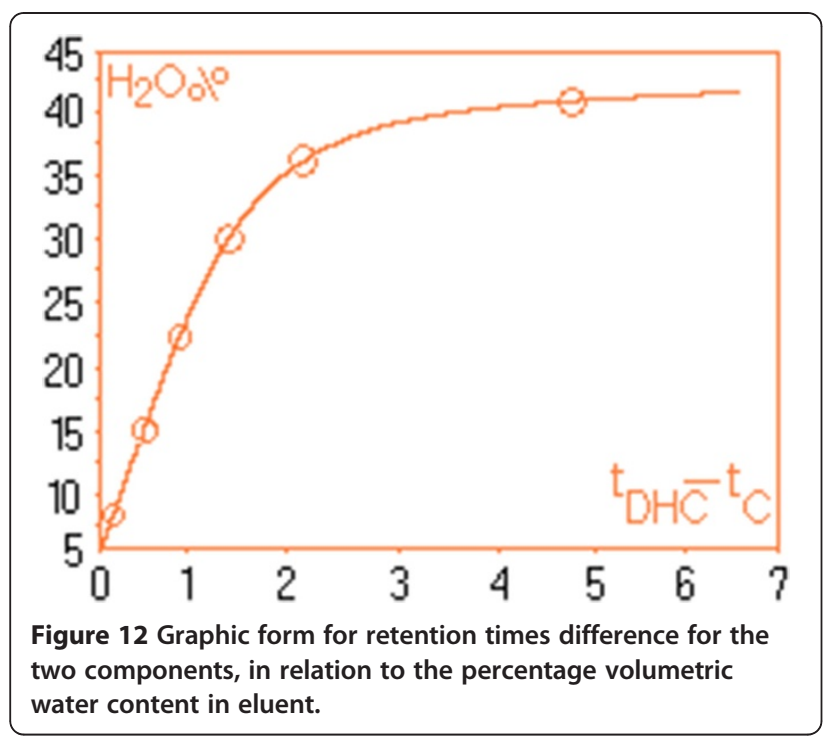

proper mixing. Samples were then removed from the heat block, centrifuged for $5 \mathrm{~min}$ in a Rotofix 32 A EC 34.1 centrifuge and supernatants were decanted into a $10 \mathrm{~mL}$ volumetric flask. The procedure was repeated three more times for a total of 4 extractions and the content of flask were brought to volume with DMF. Preliminary recovery trials were conducted to establish capsaicin (C) and dihydrocapsaicin (DHC) recoveries of $95 \%$ and $101 \%$, respectively.

\section{Capsaicinoid analysis for high performance liquid chromatography (HPLC)}

Samples of the extracts of $C$. аnnuum were placed into autosampler vials and used directly for HPLC analysis using a modification of the "short run" procedure of Morales [20]. The chromatograms were performed with a unit from Jasco, equipped with a programmable pump unit (PV-980 type), UV-970 type optical absorption

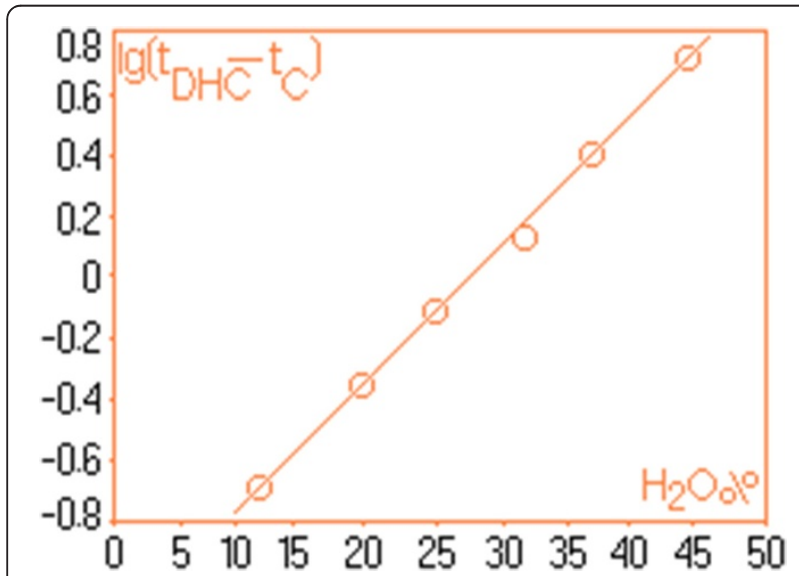

Figure 13 Chromatogram obtained after the injection of a diluted $C$. annum extract, rapport 1:10.
Table 2 Content of capsaicin and dihydrocapsaicin in C. annuum

\begin{tabular}{|c|c|c|c|c|}
\hline No. & $\begin{array}{l}\text { Aria } C \\
(\mu \mathrm{V} \cdot \min )\end{array}$ & $\begin{array}{l}\text { C in extract } \\
(\mathrm{mg} / \mathrm{mL})\end{array}$ & $\begin{array}{l}\text { Aria DHC } \\
(\mu \mathrm{V} \cdot \min )\end{array}$ & $\begin{array}{l}\text { DHC in extract } \\
(\mathrm{mg} / \mathrm{mL})\end{array}$ \\
\hline 1 & 2544217.6 & 6.843 & 1322642.7 & 1.578 \\
\hline 2 & 2583310.2 & 6.948 & 1364409.0 & 1.637 \\
\hline 3 & 2338947.5 & 6.290 & 1277005.4 & 1.533 \\
\hline 4 & 2511509.0 & 6.755 & 1320163.7 & 1.584 \\
\hline 5 & 2462441.1 & 6.623 & 1255441.2 & 1.507 \\
\hline 6 & 2481150.2 & 6.673 & 1266714.0 & 1.520 \\
\hline 7 & 2396704.7 & 6.446 & 1275194.6 & 1.530 \\
\hline 8 & 2555477.2 & 6.873 & 1334765.8 & 1.602 \\
\hline 9 & 2468812.0 & 6.640 & 1253386.6 & 1.504 \\
\hline 10 & 2511900.4 & 6.756 & 1288022.2 & 1.546 \\
\hline 11 & 2356115.0 & 6.337 & 1235534.9 & 1.483 \\
\hline 12 & 2505579.7 & 6.739 & 1257196.3 & 1.509 \\
\hline 13 & 2331576.0 & 6.271 & 1143057.2 & 1.372 \\
\hline 14 & 2407052 & 6.474 & 1253863.8 & 1.505 \\
\hline 15 & 2298857.3 & 6.183 & 1239700.5 & 1.488 \\
\hline 16 & 2395154.3 & 6.442 & 1140557.8 & 1.369 \\
\hline \multicolumn{3}{|c|}{ Values mean } & 6.581 & 1.517 \\
\hline \multicolumn{3}{|c|}{ Standard deviation } & 0.236 & 0.071 \\
\hline
\end{tabular}

detector having continuously adjustable wavelength between 190-900 nm, programmable agitator type LG980-0.2S and a DG-1580-54 type degassing unit.

Separations were accomplished with a C18 NUCLEOSIL 100 column, filled with particles with $5 \mu \mathrm{m}$ diameter. The samples used in the testing phase were fragments of $C$. annuum extract obtained randomly from different batches. In order to establish the appropriate eluent composition for separation of the two components under discussion, and for their isolation from other components present in the sample, dedicated studies were reported [21], concerning the chromatographic migration of capsaicin and dihydrocapsaicin at progressively increasing polarity of the mobile phase [22]. In all determinations methanol-water mixtures of different compositions were used. The polarity of eluent was related to the volumetric percentage of water in the mixture. The components leaving the column were monitored at $220 \mathrm{~nm}$ [23]. The eluent flow throughout all the experimental series was of $1 \mathrm{~mL} /$ minute.

\section{Competing interests}

The authors declare that they have no competing interests.

\section{Authors' contributions}

$\mathrm{MB}$ conceived the study, participated in the design and co-ordination of the experiments and data interpretation and helped draft the manuscript. AC and SP produced samples, performed data analysis and data interpretation. All authors have equal rights and all authors read and approved the final manuscript. 


\section{Acknowledgements}

The authors thank Prof. Zoltan Szabadai, MD, PhD. for helpful discussions and critical reading of the manuscript.

\section{Author details}

${ }^{1}$ Chemistry and Vegetal Biochemistry, Banat's University of Agricultural Sciences and Veterinary Medicine from Timisoara, Calea Aradului no. 119, 300645 Timisoara, Romania. Faculty of Pharmacy, "Victor Babes" University of Medicine and Pharmacy, 2A Eftimie Murgu Square, Timisoara 300041 Romania. ${ }^{3}$ Faculty of Medicine, Department of Hygiene, "Victor Babes" University of Medicine and Pharmacy, Bd. Victor Babes, no. 16, 300226 Timisoara, Romania.

Received: 8 November 2012 Accepted: 29 November 2012 Published: 4 December 2012

\section{References}

1. Kawabata F, Inoue N, Yazawa S, Kawada T, Inoue K, Fushiki T: Effects of $\mathrm{CH}-19$ sweet, a non-pungent cultivar of red pepper, in decreasing the body weight and suppressing body fat accumulation by sympathetic nerve activation in humans. Biosci Biotechnol Biochem 2006, 70:2824-2835.

2. Othman ZAA, Ahmed YBH, Habila MA, Ghafar AA: Determination of capsaicin and dihydrocapsaicin in Capsicum fruit samples using high performance liquid chromatography. Molecules 2011, 16:8919-8929.

3. Hachiya S, Kawabata F, Ohnuki K, Inoue N, Yoneda H, Yazawa S, Fushiki T: Effects of $\mathrm{CH}-19$ Sweet, a non-pungent cultivar of red pepper, on sympathetic nervous activity, body temperature, heart rate, and blood pressure in humans. Biosci Biotechnol Biochem 2007, 71:671-676.

4. Turgut C, Newby BM, Cutright TJ: Determination of optimal water solubility of capsaicin for its usage as a non-toxic antifoulant. Environ Sci Pollut Res Int 2004, 11:7-10.

5. Lee BL, Su J, Ong CN: Monomeric C18 chromatographic method for the liquid chromatographic determination of lipophilic antioxidants in plants. J Chromatogr A 2004, 1048:263-267.

6. Nwokem CO, Agbaji EB, Kagbu JA, Ekanem EJ: Determination of capsaicin content and pungency level of five different peppers grown in Nigeria. NY Sci J 2010, 3:17-21.

7. Karnka R, Rayanakorn M, Watanesk S, Vaneesorn Y: Optimization of high-performance liquid chromatographic parameters for the determination of capsaicinoid compounds using the simple method. Anal Sci 2002, 18:661-665.

8. Szolcsanyi J: Forty years in capsaicin research for sensory pharmacology and physiology. Neuropeptides 2004, 38:377-384.

9. Ha J, Seo HY, Shim YS, Nam HJ, Seog H, Ito M, Nakagawa H: Rapid method for the determination of capsaicin and dihydrocapsaicin in Gochujang using ultra-high-performance liquid chromatography. J AOAC Int 2010, 93:1905-1911.

10. Backonja MM, Malan TP, Vanhove GF, Tobias JK: NGX-4010, a high-concentration capsaicin patch, for the treatment of postherpetic neuralgia: A randomized, double-blind, controlled study with an open-label extension. Pain Med 2010, 11:600-608.

11. Zhang Q, Hu J, Sheng L, Li Y: Simultaneous quantification of capsaicin and dihydrocapsaicin in rat plasma using HPLC coupled with tandem mass spectrometry. J Chromatogr B Analyt Technol Biomed Life Sci 2010, 878:2292-2297.

12. Douat J, Vachon P, Beaudry F: Characterization of in vitro metabolism of capsazepine, a vanilloid transient receptor potential channel antagonist, by liquid chromatography quadrupole ion trap mass spectrometry. Biomed Chromatog 2011, 25:479-492.

13. Reyes-Escogido ML, Gonzalez-Mondragon EG, Vazquez-Tzompantzi E: Chemical and pharmacological aspects of capsaicin. Molecules 2011, 16:1253-1270

14. Peng A, Ye $H$, Li X, Chen L: Preparative separation of capsaicin and dihydrocapsaicin from Capsicum frutescens by high-speed counter-current chromatography. J Sep Sci 2009, 32:2967-2973.

15. Garcés-Claver A, Gil-Ortega R, Alvarez-Fernández A, Arnedo-Andrés MS: Inheritance of capsaicin and dihydrocapsaicin, determined by HPLC-ESI/MS, in an intraspecific cross of Capsicum annuum L. J Agric Food Chem 2007, 55:6951-6957.
16. Singh $S$, Jarret R, Russo V, Majetich G, Shimkus J, Bushway R, Perkins B: Determination of capsinoids by HPLC-DAD in Capsicum species. $J$ Agric Food Chem 2009, 57:3452-3457.

17. Caunii A, Pribac G, Grozea I, Gaitin D, Samfira I: Design of optimal solvent for extraction of bio-active ingredients from six varieties of Medicago sativa. Chem Cent J 2012, 6:123.

18. Sanatombi K, Sharma GJ: Capsaicin content and pungency of different Capsicum spp. cultivars. Not Bot Hort Agrobot Cluj 2008, 36:89-90.

19. Dong X, Liu Z, Li B, Wang K: Preparation of three capsaicinoid components using preparative high performance liquid chromatography. Se Pu 2008, 26:366-369.

20. Morales A, Ruiz I, Oliva J, Barba A: Determination of sixteen pesticides in peppers using high-performance liquid chromatography/mass spectrometry. J Environ Sci Heal B 2011, 46:525-529.

21. Li J, Long XY, He L, Liu F, Shu JQ: Determination of capsaicin in Pheretima aspergillum from different habitats by RP-HPLC. Zhong Yao Cai 2006, 29:448-449.

22. Chanthai S, Juangsamoot J, Ruangviriyachai $C$, Techawongstien S: Determination of capsaicin and dihydrocapsaicin in some chilli varieties using accelerated solvent extraction associated with solid-phase extraction methods and RP-HPLC-fluorescence. E J Chem 2012, 9:1550-1561.

23. Parrish M: Liquid chromatographic method of determining capsaicinoids in Capsicums and their extractives: collaborative study. J Assoc Off Anal Chem 1996, 79:738-745.

\section{doi:10.1186/1752-153X-6-146}

Cite this article as: Butnariu et al.: Reverse phase chromatographic behaviour of major components in Capsicum Annuum extract. Chemistry Central Journal 2012 6:146.

Publish with ChemistryCentral and every
scientist can read your work free of charge
"Open access provides opportunities to our
colleagues in other parts of the globe, by allowing
anyone to view the content free of charge."
W. Jeffery Hurst, The Hershey Company.
- available free of charge to the entire scientific community
- cited in PubMed and archived on PubMed Central
- yours - you keep the copyright
Submit your manuscript here:
http://www.chemistrycentral.com/manuscript/

